\title{
Tópicos sobre curadoria
}

Ivair Reinaldim*

\begin{abstract}
RESUMO: Este ensaio analisa alguns princípios referentes à curadoria, contextualizando-a historicamente ao mesmo tempo em que aborda aspectos relativos à sua prática no contexto contemporâneo: a natureza de seu ofício, sua condição intermediária entre profissão e função, os diferentes perfis, experiências e tarefas de quem a exerce. Por fim, colocam-se certas questões acerca do ensino e formação em curadoria, de modo a fomentar o debate e a tentar circunscrever o campo de ação de tal prática.
\end{abstract}

PALAVRAS-CHAVE: curadoria; crítica de arte; artes visuais.

ABSTRACT: This essay examines some principles about the practice of curatorship, contextualizing it historically at the same time that addresses aspects of their practice in the contemporary context: its nature as metier, their intermediate condition between profession and function, the different profiles, experiences and task who exercises it. Finally, puts up some questions about teaching and training curatorship in order to foster debate and trying to limit the action field of that practice.

KEYWORDS: curatorship; art criticism; visual arts

\footnotetext{
* Ivair Reinaldim é doutor em Artes Visuais, linha de pesquisa História e Crítica de Arte, pela Escola de Belas Artes da UFRJ. Professor adjunto do Departamento de História e Teoria da Arte e do Programa de Pós-Graduação em Artes Visuais da EBA-UFRJ. Atua como pesquisador e curador independente. Desenvolve o projeto de pesquisa Estudos Curatoriais: perspectivas atuais e históricas. Foi membro da comissão de seleção e premiação da categoria "curadoria" na 5a edição do Prêmio Marcantonio Vilaça (2014-2015), orientador do programa Aprofundamento em Curadoria da Escola de Artes Visuais do Parque Lage (2014) e membro da comissão curatorial da Galeria de Arte do Instituto Brasil-Estados Unidos (2009-2013).
} 
Embora o termo "curador" tenha surgido e adquirido proeminência em um período relativamente recente, considerando-se a configuração histórica do sistema de artes, a prática curatorial a cada ano vem ganhando maior visibilidade e reconhecimento social. Em um meio onde há número crescente de curadores atuantes, dos mais experientes aos em início de formação, dos vinculados a instituições aos ditos "independentes", dos que a exercem de maneira regular àqueles que o fazem apenas ocasionalmente, entretanto, constata-se que ainda há pouca ciência em relação ao histórico da curadoria, seus princípios, abrangência e limites. A euforia e o desconhecimento contribuem para a constância de situações clichês acerca das práticas curatoriais e têm dificultado a problematização de um estado atual de coisas, sobretudo em relação ao processo de espetacularização no meio de artes visuais. Acompanhamos a profusão de bienais, centros culturais, feiras, galerias e editais de exposições e residências, muitas vezes, sintoma do vínculo cada vez maior da cultura com os interesses do mercado - período nomeado, a partir da segunda metade do século XX, como "capitalismo cognitivo" (convém reforçar que tal situação tende a favorecer o aumento de oportunidades de atuação para curadores). No entanto, se o crescimento de investimentos em cultura parece algo a se comemorar, isso não significa que museus, bibliotecas e mesmo acervos públicos tenham recebido a mesma atenção e investimentos por parte de governos, empresas e fundações cabe-nos o alerta.

Poderíamos, isso posto, considerar a afluência e circulação de "enlatados de curadoria" - com maneiras e soluções padronizadas na escolha de títulos, definição dos temas, seleção de artistas, arranjo espacial das obras, divulgação (muitas dessas iniciativas tornam-se "imagens" amplamente difundidas, que documentam e ao mesmo tempo substituem a vivência direta com obras e espaços expositivos), etc. Nesse contexto quase tudo se resolve a partir dos interesses do marketing cultural e das assessorias de imprensa. Torna-se simples, enfim, apreender rapidamente fórmulas e modos estandardizados de concepção e apresentação curatorial. Em linhas gerais falamos de exposições e projetos que, passado o estardalhaço em torno dos mesmos, pouco contribuem ou acrescentam às experiências que produzem, seja em termos de construção de sentidos para as obras, seja no que se refere à formação e trajetória, crescimento intelectual e artístico, ou mesmo vivência estética daqueles direta ou indiretamente neles envolvidos - artistas, profissionais variados, público em geral, instituições. Isso sem 
mencionar as possíveis contribuições futuras à história da arte. Projetos que alimentam números, são produzidos para consumo instantâneo, promovem o entretenimento como regra e concretamente pouco agregam em termos qualitativos.

É preciso reforçar que não se trata de persistir em uma análise pessimista ou negar que qualquer contribuição, por menor que seja, não deixa de ser uma contribuição. Contudo, há muitas exposições que se afastam desse diagnóstico, apresentam novos modos de abordar e pensar velhos temas, problemáticas e obras, estimulam reflexão e debate sobre arte, cultura, política e sociedade, e há igualmente aquelas que, em meio à necessidade e à exigência do espetacular, conseguem reverter sua própria condição, curadorias cujo projeto às vezes reverbera mais à posteriori do que no momento de sua ocorrência, ou mesmo em contextos diferentes - vide a 24a Bienal de São Paulo, dita "Bienal da Antropofagia" (1998), e sua grande repercussão internacional. ${ }^{1}$ A preocupação aqui é justamente reforçar uma conjuntura para, a partir dela, propor aproximações com aquilo que se tem como parâmetro qualitativo.

Se os processos de espetacularização e mercantilização da cultura são fenômenos recorrentes na esfera global, no contexto brasileiro, além dessas problemáticas, curadores que buscam o desenvolvimento e aprimoramento de sua prática também enfrentam dificuldades específicas, a saber: 1. a existência de poucas publicações em língua portuguesa sobre o tema curadoria (traduções e textos originais), em comparação à bibliografia em outros idiomas, sobretudo em língua inglesa, e a carência de muitos dos títulos (nacionais e internacionais) em acervos de bibliotecas; 2 . formação autodidata ou por meio de cursos de curta e média duração, nem sempre vinculados a conhecimentos mais profundos de história e teoria da arte, o que atualmente, em certos contextos, vem sendo considerado desnecessário aos aspirantes a curador(a), com interesses voltados para uma formação de caráter interdisciplinar (embora, em muitos casos, de viés excessivamente generalista) e de capacitação técnica - desse modo, aprende-se o passo-a-passo e o repertório relativos ao processo, mas quase sempre falta estofo mais específico em relação ao objeto com o qual se trabalha; 3. a existência de poucos postos de trabalho para curadores em instituições museológicas, bem como de acervos públicos consistentes, o que obriga curadores a investirem energia e a se dedicarem a grande número de projetos de curta duração, quase sempre sem tempo hábil para pesquisa, reflexão e desenvolvimento consistente das propostas, tendendo a privilegiar acervos de 
coleções particulares; 4. por fim, debates mais circunscritos, de modo geral, aos grupos de estudos, conferências promovidas por universidades, escolas, museus e centros culturais, situações de diálogo e contato direto entre curadores mais experientes e seus assistentes, sem que haja amplo estímulo para um debate público sobre a prática curatorial e os rumos que vem sendo seguidos por aqueles que exercem tal função.

Cabe reconhecer ainda que o termo "curadoria" extrapolou os limites das artes visuais, sendo empregado em outras áreas, sempre que presumir ideias como gestão, organização e seleção (vide sua recorrência na gastronomia, moda, televisão, música, em festivais de cinema, teatro e dança, etc.). O uso banalizado reforça o estatuto social da prática; no entanto, pouco contribui para definir seus sentidos e sua natureza. Parece mais inseri-lo em um estado de indeterminação, ao esgarçá-lo de tal modo que fica difícil compreender o que de fato significa, identifica ou abarca. Esse esgarçamento pode igualmente ser constatado no que tange a outras categorias do meio de artes visuais, como "artista", "museu" e "crítica", por exemplo, que acabam assumindo, mesmo no senso comum, feições excessivamente permissivas. Afinal, a que e a quem esse estado de coisas serve?

É preciso reforçar ainda que aquele que pratica a curadoria acaba visto de maneiras diversas no sistema de artes visuais: o artista Artur Barrio, por exemplo, refere-se ao curador como "uma necessidade desnecessária", enquanto para outros profissionais trata-se de um colaborador ou mesmo um "agente" fomentador, que contribui para o diálogo entre artistas, instituições e público, ou ainda, um profissional autoritário, representante e detentor de poder simbólico, capaz de legitimar obras e artistas e agregar valor a instituições e coleções. Certamente, há depoimentos para todos os gostos e percepções. ${ }^{2} \mathrm{O}$ que importa nesses diferentes pontos de vista é a constatação da similaridade entre a condição outrora ocupada pelo crítico de arte seja como quem emite juízo crítico (caricatamente, legitimando ou condenando obras e artistas), como mediador na construção de sentidos ou como parceiro, incentivador e colaborador de artistas - e a atividade exercida atualmente pelo curador, o que reforça uma relação simbiótica entre o que outrora se entendia como crítica de arte e o que atualmente compreende-se como curadoria. A prática curatorial atual, então, mais do que uma decorrência da conservação de acervos e da museologia, seria um desdobramento do exercício da crítica, passando de um veículo (sobretudo o jornal) para outros (exposição, catálogo, livro, etc.). 


\section{A curadoria de arte / A arte da curadoria}

De modo mais específico, contrapor "curadoria de arte" à "arte da curadoria" é pensar no mínimo em duas possibilidades de interpretação: a primeira procura evocar a ideia de curadoria de artes visuais como uma prática "de bastidores", onde o que prevalece são sempre obras e artistas - ou seja, a "arte" - e não o contrário, a noção do curador como criador, sobrepondo-se a tudo e a todos, fazendo da própria exposição sua grande obra (a estimável "arte da curadoria"). Essa tendência persiste, de modo geral, no meio de artes visuais, sempre que o tema de uma exposição ou projeto (e a figura do curador, é claro) torna-se assunto privilegiado de debate, mais que as obras expostas ou as relações que podem advir das mesmas. Para Hans Ulrich Obrist, um dos mais renomados (ou badalados) curadores da atualidade, "artistas e suas obras não devem ser usados para ilustrar uma proposta ou premissa curatorial à qual estão subordinados" (OBRIST, 2014, p. 47), sendo refratário à ideia de que o curador é uma figura criativa. Outro entendimento possível refere-se à noção da curadoria como uma "arte", no sentido arcaico do termo, ou seja, como um ofício. ${ }^{3}$ A acepção evidenciaria que, mais do que uma vocação, o processo permanente de construir-se enquanto curador exige estudo, conhecimento, acúmulo de experiências, aprimoramento e alguma dose de autorreflexão, entre outras coisas.

Convém fazer uma breve arqueologia dessa prática e do termo que a nomeia, de modo a bem compreender de que se fala ao referir-se à palavra curadoria. Na língua portuguesa os dicionários assinalam que curador é quem administra bens alheios por encargo judicial. Sua raiz etimológica latina é curare, palavra originalmente utilizada no império romano para designar um oficial administrativo responsável pela supervisão de obras públicas. A acepção atual relacionada às artes visuais - "cuidar de" - surgiu a partir da emergência dos museus no século XVIII e, em linhas gerais, assinala tanto um funcionário responsável por um departamento específico de uma instituição quanto alguém que organiza exposições. O termo englobou o que na língua francesa costumava estar separado em duas terminologias: o conservateur de musée ou du patrimoine (conservador de museu ou do patrimônio), aquele que é responsável pelo inventário, estudo, documentação, conservação, difusão das coleções de um museu (ou do patrimônio), assumindo funções administrativas e organizando exposições permanentes e temporárias, com o objetivo de colocar em evidência a coleção sob sua salvaguarda, seja em 
relação ao público em geral ou frente à comunidade científica; e o commissaire des expositions (comissário de exposições), ademais chamado curateur (em paralelo ao termo curator, em língua inglesa), aquele que concebe intelectualmente uma exposição temporária, ficando responsável pela deliberação do tema ou problemática abordada, escolha das peças a serem expostas, definição da disposição das mesmas no espaço e divulgação junto ao público (projeto educativo, textos, catálogo), podendo ou não estar vinculado a uma instituição - nesse caso, como um conservateur des collections (conservador de coleções). ${ }^{4}$ Com o advento do curador dito independente essa realidade mudou, mesmo na França, e as duas funções encontram-se geralmente confundidas. Mas como surgiu essa nova modalidade de atuação, que redefiniu o entendimento da prática curatorial?

A princípio, é importante manter-se no âmbito semântico. Hans Ulrich Obrist tende a preferir o uso da expressão curador freelancer para denotar aquele indivíduo que trabalha de modo livre, sem vinculação fixa com um museu, fundação ou coleção, uma vez que "independente" seria um termo questionável: o fato de não estar subordinado a uma instituição, não quer dizer que quem exerça curadoria não tenha outros vínculos e compromissos, explícitos ou mesmo subjacentes a sua prática - do mesmo modo, curadores institucionais devem resguardar sua autonomia frente a imposições ou contrassensos que possam advir de patrocinadores, conselhos consultivos ou mesmo diretores da entidade a qual estão vinculados. Considerando-se ou não a problemática ligada ao uso do termo, a noção de "curador independente" surgiu por volta de 1970 quando o suíço Harald Szeemann, então curador da Kunsthalle de Berna, organizou a emblemática mostra When Attitudes Become Form: Works - Concepts - Processes - Situations - Information (1969), uma das primeiras iniciativas de reconhecimento institucional da produção artística de caráter experimental da década de 1960. Após desacordos expressos pela diretoria da Kunsthalle frente às diversas polêmicas geradas pela mostra junto ao público e à municipalidade de Berna, Szeemann foi destituído de seu cargo. A partir de então, fundou sua Agency for Intellectual Guest Labour e passou a desenvolver projetos de modo autônomo, ora apresentando-os às instituições, ora sendo comissionado para elaborar e executar uma nova proposta. ${ }^{5}$ Como desdobramento, inúmeros outros curadores seguiriam seus passos, reconfigurando as linhas gerais de seu ofício.

No caso brasileiro, poucos profissionais conseguem exercer a prática de curadoria vinculados a uma instituição. Um dos pioneiros foi Walter Zanini, que ficou à frente do Museu de Arte Contemporânea da USP, entre 1963 e 1978, e assumiu o cargo de diretor artístico das 16a e 
17ª Bienais de São Paulo (1981 e 1983). Se há uma tendência da historiografia em identificar na figura de Zanini a origem da curadoria no país, é preciso reforçar que no contexto carioca, na passagem dos anos 60 para os 70, havia Frederico Morais e Roberto Pontual - ambos assumindo cargos como coordenadores de cursos e de exposições, respectivamente, no Museu de Arte Moderna do Rio de Janeiro. Frederico Morais seria um caso a se considerar por sua natureza experimental, tanto no contexto institucional, com a proposição dos Domingos da Criação (1971) - eventos realizados na área externa do museu e que extrapolavam sua dimensão pedagógica -, quanto no contexto das exposições e projetos autônomos, como a mostra seminal Do Corpo à Terra (1970), realizada no Parque Municipal de Belo Horizonte. Se na época não havia a utilização do termo "curador", não quer dizer que não seja possível observar nesses exemplos as primeiras evidências da prática no Brasil, sem contudo reivindicar qualquer pioneirismo por parte de um ou de outro. ${ }^{6}$

É preciso salientar que em um processo de investigação arqueológica, há sempre o risco de voltar-se mais e mais no tempo, deduzindo paralelos históricos com certas práticas contemporâneas. Entretanto, o ponto de vista historicista pouco se atém a certas especificidades dessas práticas e, embora haja possíveis similaridades entre a noção de curadoria e certas proposições de períodos longínquos da história, as diferenças acabam sendo consideráveis e pertinentes. Fato é que a curadoria passou a ser importante no momento em que museus e, sobretudo, exposições tornaram-se locais e situações referenciais para o sistema de arte e qualquer paralelo anterior apresenta-se mais como um conjunto de "antecedentes" do que ação curatorial propriamente dita.

\section{Curadoria como função / Curadoria como profissão}

Se a história da curadoria demarcou uma divisão inicial entre o conservador de museu e o comissário de exposições, essa mesma história - tendo Harald Szeemann como precursor, mas de modo mais acentuado, a partir da década de 1990 - apresenta a emergência do curador como um profissional liberal, um prestador de serviços, muitas vezes detentor de saber técnico especializado. Nesse sentido, torna-se importante verificar se a curadoria pode ser entendida como profissão, reconhecida na cadeia econômica da cultura, ou se seria de fato uma função exercida por profissionais provenientes de diversas áreas, em determinada conjuntura, o que minimizaria a importância da especialização. 
Caso seja entendida como profissão, é preciso considerar a existência de cargos ligados à curadoria em certos departamentos de museus, concentrados em uma época, linguagem ou técnica e mesmo área geográfica - o que é comum em instituições na Europa e também nos Estados Unidos - ou mesmo a curadoria geral do museu (o equivalente ao conservateur de musée), como o que ocorre mais frequentemente no Brasil, em que uma única pessoa, muitas vezes acompanhada de assistentes, é responsável por todas as coleções abrigadas na instituição. Ao fazê-lo, fica evidente que o objetivo seria igualar o ofício da curadoria ao quadro das profissões reconhecidas e regulamentadas pela legislação, o que exige algumas considerações.

Uma profissão é uma ocupação especializada, em que a atividade individual possui autonomia relativa, organizada em torno de associações coletivas, que controlam o campo de atividade por meio de sistemas de regulamentação (código de ética, educação especial e qualificada, programas de formação e estágio profissional). Nesse sentido, sem a existência de um número considerável de cursos de graduação e pós-graduação na área e de estruturas de representação coletiva, torna-se difícil o reconhecimento da curadoria como profissão. Mesmo em países onde há cursos específicos (em geral, mestrados com viés profissionalizante), estes não provêm qualificação suficiente para o exercício da atividade, segundo argumento de Dominic Willsdon, professor do mestrado em curadoria do Royal College of Art, em Londres. ${ }^{7}$

No caso francês, a diversificação do campo, com a emergência do curador independente, tendeu a colocar em crise a profissão regulamentada do conservateur de musée. Para Nathalie Heinich e Michael Pollak, a partir dessa nova modalidade de atividade, o "curador-como-autor" passou a "performar uma função", em contraposição ao profissional que ocupa um posto de trabalho fixo. O curador independente poderia ser compreendido, então, como modelo de antiprofissional, uma vez que seu estatuto seria sempre o do criador individual, cuja "assinatura" acaba influenciando a recepção de seus projetos, e não a de um profissional regulamentado por convenção social, cuja instituição em que trabalha tenderia a orientar certos posicionamentos, escolhas e ações. ${ }^{8}$

Assim, o entendimento da curadoria como função estaria associado à ideia de um prestador de serviços, atuando a partir da demanda de instituições e editais, ou mesmo de iniciativas próprias e de espaços independentes, tendendo a ser comum considerar que profissionais com diferentes formações e profissões possam desenvolver de modo esporádico (ou 
contínuo) projetos de curadoria, desde teóricos em geral, docentes, museólogos e mesmo artistas. Nesse sentido, não haveria um sujeito exemplar, exclusivamente dedicado à prática curatorial - exceto nas situações em que há um vínculo institucional regular -, mas profissionais que em certas condições exercem tal função, o que tende a ser mais comum no caso de projetos de exposições temporárias, tanto em centros culturais, museus, galerias, feiras ou mesmo em espaços alternativos (ateliês, locais não institucionalizados ou projetos ao ar livre, etc.). Se essa diversidade é capaz de enriquecer as abordagens e feições da curadoria, no entanto, pode contribuir para torná-la bastante condescendente, dependendo das condições em que é praticada (de fato, quanto mais permissivo o meio, menos seus integrantes são questionados em relação a suas práticas, funções ou mesmo posições, o que vale para curadores, críticos, historiadores, diretores de instituições, galeristas, artistas, etc.).

\section{Tornar-se curador: perfis e tarefas}

A prática da curadoria coloca certas questões referentes ao perfil de quem atua nessa área, atividade em constante transformação, em consonância com as mudanças ocorridas no meio cultural e no sistema de arte. Como a princípio não haveria regras precisas para o exercício do que nem sempre se adequa ao formato de profissão regulamentada, é possível identificar visões divergentes sobre os requisitos necessários para se tornar curador. Algumas características identificadas em outras análises poderiam ser aqui enumeradas, das mais subjetivas às mais pragmáticas: curiosidade, imaginação, abertura para o mundo, flexibilidade, singularidade, sensibilidade, apuramento do olhar, saber ver e ouvir, ter algo a dizer, dedicação, senso de responsabilidade, atitude inquisitiva, tomada de posição, ousadia, formulação de pontos de vista fortes e pessoais, poder de negociação, diplomacia, domínio de idiomas, gosto por viagens, personalidade empreendedora, habilidades empresariais, consistente formação humanística interdisciplinar, experiência fundada em reflexão teórica, frequência em museus, galerias, feiras e bienais, contato constante com obras e artistas, etc. Concordando-se ou não com todos os atributos aqui listados, para além de estabelecer uma descrição idealizada ou mesmo estereotipada do curador, há duas noções de natureza mais conceitual que tendem a ser evocadas quando se fala na sua prática: de um lado, a importância (ou não) do conhecimento aprofundado em história e teoria da arte e, por outro, a relação mútua entre curadoria e crítica de arte. 
Desde os anos 1990, há uma tendência em certas instituições que promovem cursos de curadoria a considerar que a formação em teoria e história da arte tenha sido uma condição identificável e essencial apenas para os primeiros curadores, sobretudo aqueles que, em sua maioria, assumiram cargos junto a museus. Em paralelo ao perfil mais experimental da arte produzida na segunda metade do século XX, essa obrigatoriedade passou a ser gradualmente substituída pelo interesse por campos variados do saber, como filosofia, semiologia, antropologia, etnografia, sociologia, ciência política, psicologia, psicanálise, comunicação, etc. Hoje, muitos cursos de formação amenizam tanto uma ênfase quanto outra, ao evidenciarem maior preocupação em capacitar o jovem curador por meio de um saber especializado e de ordem prática, a partir de conhecimentos em pesquisa, museologia, cenografia, montagem, iluminação, editoração, produção e gestão de projetos, captação de recursos, etc. Assim, a especialização técnica prepara mão-de-obra qualificada para trabalhar em variados postos, seja museus, centros culturais ou mesmo feiras e galerias de arte. No entanto, essa posição tende a ser questionada por alguns curadores.

Segundo Cauê Alves, por exemplo, "espera-se da curadoria", em sentido amplo do termo, "que saiba compreender e relacionar o trabalho de arte, senão na história da arte, numa sequência de outros trabalhos ou no contexto de uma discussão atual", defendendo que "há pouco ou nenhum sentido na curadoria e na crítica que não possui embasamento histórico e teórico" (RAMOS, 2010, p. 44). Se a prática curatorial não instrumentaliza explicitamente um saber histórico, deve-se ter em mente que este muitas vezes orienta a tomada de decisões e a abordagem do curador. A curadoria seria um modo de produzir-se história da arte (ou mesmo história da cultura) por meio das relações que podem ser estabelecidas entre objetos expostos (ou postos em evidência), constituindo-se importante mecanismo tanto de questionamento das narrativas engessadas quanto de proposição de visões renovadas sobre obras, artistas, períodos artísticos, etc. Fato é que muitas das recentes abordagens revisionistas da história da arte têm surgido em contextos de curadoria de exposições e produção ensaística de textos de catálogo, talvez por apresentarem maior liberdade em relação às publicações e pesquisas essencialmente teóricas, em que nem sempre há o enfrentamento direto das obras.

A prática curatorial pode igualmente ser compreendida como desdobramento da crítica de arte, atividade historicamente exercida por pessoas de diferentes formações (literatura, filosofia, jornalismo, direito, artes visuais, etc.). Uma vez que atitude reflexiva é algo esperado de todo curador, espera-se que suas avaliações sejam decorrentes da experiência direta com 
obras e/ou artistas, mais do que em princípios teóricos tomados a priori e aplicados indiscriminadamente a seu objeto - o que em geral costuma ocorrer em curadorias cujas obras selecionadas submetem-se e ilustram teses de seus autores. O curador, sobretudo aquele que se dedica à produção contemporânea, tende a conviver com artistas e seus processos de trabalho, frequentando ateliês, relacionando-se e debatendo questões variadas de seu próprio tempo. Ou seja, a curadoria também pode ser entendida como uma modalidade de crítica, fruto das transformações que a figura tradicional do crítico de arte sofreu e vem sofrendo no contexto contemporâneo.

A afirmação de que o curador necessita apresentar capacidade de mediação reside em mais um aspecto que o aproximaria da experiência crítica. Toda curadoria é, em primeiro lugar, mediação entre a singularidade das obras e poéticas artísticas e os diálogos que podem ser construídos a partir delas, respeitando-se o sentido próprio que cada obra apresenta (seus aspectos intrínsecos e extrínsecos) e as novas possibilidades de significação decorrentes de uma análise em conjunto. É o que reforça Paulo Herhenhoff, ao afirmar que "curadoria é um campo do pensamento crítico, "relacionado diretamente" com a presença e a corporeidade da obra" (HERKENHOFF, 2008, p. 23). É importante lembrar ainda que o curador produz mediação das obras tanto em relação ao espaço por elas ocupado quanto ao público da exposição ou proposição, muitas vezes coordenando e fornecendo os parâmetros para o projeto educativo.

Essa predisposição mediadora abrange ainda a capacidade de negociação decorrente de todo projeto de caráter coletivo e colaborativo, o que inclui artistas, representantes de instituições, colecionadores, profissionais envolvidos diretamente com a produção (em todas as suas instâncias), etc. A relação entre curadores e artistas pode ser útil para exemplificar como o trabalho colaborativo é importante no que tange à concepção de uma exposição, tanto quanto os problemas que possam decorrer daí. O curador Olu Oguibe ressalta a importância de "um relacionamento simbiótico de respeito e compreensão mútua, em que os artistas veem o curador como um catalisador útil, e não como um obstáculo; um colaborador, e não um interlocutor inconveniente; um sócio no empreendimento de construir, e não um mero empresário usurpador que fica no meio do caminho" (OGUIBE, 2004, p. 17). Trata-se, para ele, de uma relação de respeito e interdependência, mais do que de serventia e usufruto. A vontade de colaboração, de relacionamento horizontalizado com artistas e profissionais que cooperam na realização de um projeto, tende a ser o perfil mais indicado para aquele que se propõe curador. 
Finalmente, seja através da importância da história da arte ou do caráter crítico necessário para sua prática, torna-se primordial que o curador seja em essência um pesquisador, aprofundando questões teóricas, investigando aspectos relacionados à arte, imagem, representação, estudos culturais, aliados a um interesse e conhecimento de pautas sociais, políticas, ambientais, etc. de seu tempo, confrontando-se permanentemente com obras e proposições de viés experimental, dialogando com artistas e seus processos, articulando e construindo sentidos renovados para o objeto ao qual se dedica.

\section{A guisa de conclusão: para iniciar o debate}

Em princípio, como já explicitado, a tarefa mais importante de um curador seria cuidar, zelar e defender os interesses de artistas e dos trabalhos de arte - e não compactuar e agir em prol de preferências pessoais, patrimonialistas ou mercadológicas. Paralelamente a essa dimensão zelosa, haveria uma série de outras demandas: investigar, organizar, inventariar, conservar obras e coleções; administrar acervos, instituições e projetos; organizar e supervisionar exposições permanentes e temporárias; conhecer e divulgar coleções, obras e artistas; produzir conhecimento e documentação por meio de exposições, ensaios, edição de livros e catálogos; organizar e participar de conferências, ciclos de ideias, cursos sobre arte e cultura; mediar e contribuir para a formação de público; etc. Em cada uma dessas atividades, o curador age, agencia, desempenha relações sociais, de modo a ampliar e compartilhar um conjunto de conteúdos simbólicos, a partir da dimensão e do alcance público de suas proposições.

No Brasil há curadores experientes, com formações plurais e experiências adquiridas na medida em que foram desenvolvendo suas ações: assumiram cargos institucionais, organizaram exposições temporárias, supervisionaram projetos, sem, no entanto, ter uma formação oficial em curadoria (embora alguns tenham frequentado cursos em outros países). Contrapondo-se a essa trajetória, atualmente, jovens curadores podem tanto recorrer a cursos de formação em museus, escolas livres, disciplinas de cursos de graduação e, mais especificamente, cursos de pós-graduação lato sensu, quanto a oportunidades práticas, seja fazendo estágios em museus, atuando em espaços independentes ou organizando seus próprios projetos de curadoria. A partir dessas diferenças geracionais e conjunturais de formação e aquisição de experiências, cabe uma série de indagações: É possível ensinar curadoria? Se sim, de que 
modo isso pode ser feito? Cursos de formação em curadoria transmitem saberes específicos e habilidades técnicas, capacitando indivíduos para o trabalho, ou são capazes de desenvolver pensamento sobre arte, aliado a outros saberes, concebendo a prática curatorial como uma decorrência dessa atividade reflexiva? As opções atualmente disponíveis resumem-se a um sistema de reprodução de discursos e "programas de sucesso" ou constituem-se como iniciativas capazes de instigar em seus participantes a atitude crítica e a capacidade de desenvolver novos modos de perceber velhos problemas? Talvez resida aí a dimensão essencial do debate, pois só se pode ensinar algo a partir do entendimento daquilo que se quer instruir e orientar, daquilo que se deseja como desdobramento futuro de uma prática. Refletir sobre o que o curador faz e por que o faz é uma pauta de debate que apenas se inicia.

\section{Notas}

1 Cf. HERKENHOFF, Paulo. Bienal 1998: princípios e processos. In: Marcelina, Revista do Mestrado em Artes Visuais da Faculdade Santa Marcelina, São Paulo, ano 1, vol. 1, pp. 20-36, 2008.

2 Cf.: O curador é dispensável? In: Select, Revista de Arte e Cultura Contemporânea, ano 5, ed. 22, p. 8, fev/mar 2015. Em outra publicação, a fala de Artur Barrio aparece contextualizada: “O pensamento é e sempre será eficaz, dependendo de quem o pensa e do que diz,.... principalmente do que diz. Quanto à curadoria em relação a meu trabalho, aí sim, posso dizer que o curador é uma necessidade desnecessária por justamente o perfil de meu trabalho não necessitar, não ter a necessidade de um curador." No hemisfério sul. In: Arte \& Ensaios, Revista do Programa de Pós-Graduação em Artes Visuais, EBA-UFRJ, Rio de Janeiro, ano XV, n. 17, p. 14, dez. 2008.

3 Essa ideia aparece na coletânea Sobre o ofício do curador, organizada por Alexandre Dias Ramos, para quem "a curadoria é um ofício antigo, mas uma profissão relativamente nova". Cf.: RAMOS, Alexandre Dias (org.). Sobre o ofício do curador. Porto Alegre: Zouk, 2010, p. 11.

40 commissaire des expositions francês estaria próximo ao Austerllungsmacher, ou organizador de exposições, profissional assim nomeado em países de língua alemã, e que é visto por muitos autores como aquele que mais se aproxima do perfil atual da prática curatorial.

5 Cf.: DERIEUX, Florence (ed.). Harald Szeemann: Individual Methodology. Zurich: JRP/Ringier Kunstverlag AG; Grenoble: Le Magasin - Centre Nacional d'Art Contemporain; London: Royal College of Art, 2007.

6 Se for possível indicar pioneiros na prática curatorial, como Walter Zanini, Frederico Morais e Roberto Pontual, é preciso salientar que ainda há muito a se investigar em relação a outras regiões do vasto território brasileiro, ou mesmo cruzar dados de pesquisas já realizadas com as informações aqui explicitadas.

7 WILLSDON, Dominic. Curating as a profession? In: MJ - Manifesta Journal: Journal of Contemporary Curatorship, Amsterdam, n. 4, pp. 62-67, autumn/winter 2004. 
8 HEINRICH, Nathalie; POLLAK, Michael. From Museum Curator to Exhibition Auteur: Inventing a Singular Position (1989) apud WILLSDON, Dominic. Id., p. 66

\section{Referências}

Arte \& Ensaios, Revista do Programa de Pós-Graduação em Artes Visuais, EBA-UFRJ, Rio de Janeiro, ano XV, n. 17, dez. 2008.

DERIEUX, Florence (ed.). Harald Szeemann: Individual Methodology. Zurich: JRP/Ringier Kunstverlag AG; Grenoble: Le Magasin Centre Nacional d'Art Contemporain; London: Royal College of Art, 2007.

HERKENHOFF, Paulo. Bienal 1998: princípios e processos. In: Marcelina, Revista do Mestrado em Artes Visuais da Faculdade Santa Marcelina, São Paulo, ano 1, vol. 1, pp. 20-36, 2008. [edição: Antropofágica]

MJ - Manifesta Journal: Journal of Contemporary Curatorship, Amsterdam, n. 4, autumn/winter 2004. [Teaching Curatorship]

OBRIST, Hans Ulrich. Caminhos da curadoria. Rio de Janeiro: Cobogó, 2014.

OGUIBE, Olu. O fardo da curadoria. In: Concinnitas, Revista do Instituto de Artes da Uerj, Rio de Janeiro, ano 5, n. 6, p. 17, julho 2004. [Dossiê sobre a função do curador]

RAMOS, Alexandre Dias (org.). Sobre o ofício do curador. Porto Alegre: Zouk, 2010.

Select, Revista de Arte e Cultura Contemporânea, ano 5, ed. 22, fev/mar 2015. [edição especial: Curadores] 